\title{
Analgesia multimodal preventiva en el control total de dolor en pacientes de amigdalectomía. Reporte de 51 casos
}

\author{
Carranza Cortés JL.1, Puga Flores EdC. ${ }^{1}$ \\ 1 Servicios de Salud de Nayarit, Tepic, México.
}

Introducción: El abordaje multimodal del dolor incluye la utilización de técnicas regionales o locales, con una combinación de analgésicos como los no- esteroideos (AINEs), y fármacos que inhiben la recapturación de serotonina la síntesis de prostaglandinas. El objetivo general fue determinar si existe utilidad en la aplicación de la terapia de analgesia preventiva multimodal en pacientes intervenidos de amigdalectomía, así como observar cual es el comportamiento hemodinámico.

Material y Método: Se realizó un estudio transversal, abierto, prospectivo y prolectivo. Se incluyeron pacientes con Estado Físico (ASA I-II), con un rango de edad de 6 y 45 años, sometidos a amigdalectomía y/o adeno -amigdalectomía. Antes de la inducción de la anestesia se les administro a los pacientes una infusión de dexametasona (200 mg/ $\mathrm{kg}$ ) y de ketorolaco $(1 \mathrm{mg} / \mathrm{kg})$. Posteriormente, antes de iniciar el acto quirúrgico se infiltró en los pilares amigdalinos, ropivacaína al 7,5\% (2 ml), y lidocaína con epinefrina al 2\% $(2 \mathrm{ml})$. La técnica quirúrgica fue mediante ASA fría. Se determinaron dos cortes para las variables hemodinámicas y de dolor; F1 al salir a recuperación; y F2 para la valoración de alta de la Unidad. Fueron analizadas las variables paramétricas mediante T Pareada, y las no paramétricas con Chi cuadrado (?2) con $\mathrm{p}<0,05$ respectivamente.

Resultados: Se estudiaron un total de 51 pacientes $(n=51)$, con una edad de $X=14,06 \pm D E 5$; peso de $X=47 \pm D E$ 6. Con ASA I, 49 pacientes (95,92\%), y ASA II 2 pacientes (4.08\%) -estos dos pacientes portaban Obesidad grado II-. El comportamiento hemodinámico analizado mediante T pareada, no representa diferencias estadísticamente significativas (Tabla 1).

La Evaluación de Dolor que fue mediante ?2, se reportan diferencias estadísticamente significativas; en la Fase 1 un paciente requirió medicamento de rescate -metamizol $20 \mathrm{mg} / \mathrm{kg}$-. Los datos se exhiben en la Figura 1, en una tabla de contingencia de $2 \times 2$.

Conclusiones: La terapia para el control del dolor -multimodal- preventiva-, propuesta en este estudio resulto de utilidad, en virtud que el 98,4 de los pacientes no requirió dosis analgésica de rescate, perdurando la analgesia todo el postoperatoria y hasta el alta de la unidad.

https://doi.org/10.25237/congresoclasa2019.19 